\title{
Experimental study and modeling of the influence of screw dislocations on the performance of $\mathrm{Au} / \boldsymbol{n}$-GaN Schottky diodes
}

\author{
Y. Huang, X. D. Chen, S. Fung, ${ }^{\text {a) }}$ C. D. Beling, and C. C. Ling \\ Department of Physics, The University of Hong Kong, Pokfulam Road, Hong Kong, \\ People's Republic of China
}

(Received 21 April 2003; accepted 7 August 2003)

\begin{abstract}
Current-voltage $(I-V)$ characteristics of macroscopic Schottky diodes fabricated on different GaN templates grown by metalogranic chemical vapor deposition on sapphire substrates were investigated. The number of dislocations under the Au Schottky contact was determined by atomic force microscopy combined with hot $\mathrm{H}_{3} \mathrm{PO}_{4}$ etching and the screw dislocations in the GaN films were found to have a strong influence on the reverse leakage current of the $\mathrm{Au} / n$-GaN Schottky diodes. The leakage current is increased when high-density screw dislocations exist under the $\mathrm{Au}$ Schottky contact. A model based upon the presence of dislocations at the $\mathrm{Au} / \mathrm{GaN}$ interface has been used to explain this behavior. It has been proposed that these dislocations result in the lowering of the barrier height in the localized regions, and thus significantly affect the reverse $I-V$ characteristics of the Schottky diodes. (C) 2003 American Institute of Physics.
\end{abstract}

[DOI: $10.1063 / 1.1615705]$

\section{INTRODUCTION}

$\mathrm{GaN}$ has attracted considerable interest because of its potential applications including blue/ultraviolet light emitting devices, ultraviolet detectors, ${ }^{1,2}$ field-effect transistor (FETs), and bipolar transistors. ${ }^{3-6} \mathrm{GaN}$ is desirable for electronic applications due to its high saturated electron velocities of $2 \times 10^{7} \mathrm{~cm} / \mathrm{s},{ }^{7}$ its wide band gap of $3.4 \mathrm{eV}$, its high critical breakdown field of $3 \times 10^{6} \mathrm{~V} / \mathrm{cm},{ }^{8}$ and also its stability at high temperature. Schottky barriers are one of the fundamental building blocks for electronic devices. They are used in Schottky diode rectifiers when fast switching speeds are required. Schottky barriers are also used as the control electrode to modulate the channel current in FETs. An increasing number of experiments have been recently carried out to study the characteristics of GaN Schottky contacts using different metallizations, such as $\mathrm{Ti}^{9}{ }^{9} \mathrm{Ni},{ }^{10} \mathrm{Pt},{ }^{11-13}$ and Au. ${ }^{9,14,15}$ These studies, in general, reveal that the reported properties of GaN Schottky diodes for the same metallization show a large amount of variation. This variation is undoubtedly due to differences in the sample preparation and material quality. For the case of $\mathrm{GaN}$, however, because of the lack of native substrates, heteroepitaxial GaN film fabricated nowadays usually exhibits a high dislocation density $\left(10^{8}-10^{9} \mathrm{~cm}^{-2}\right) .{ }^{16}$ The device uniformity and reproducibility, especially the reverse leakage current of GaN-based devices, are strongly influenced by the dislocations in the GaN film, ${ }^{17-21}$ and more importantly, the reverse-bias leakage is not sensitive to the barrier height measured at forward bias for $n$-GaN Schottky diodes. ${ }^{19}$ It is known that this undesired reverse-bias leakage current remains an obstacle for many electronic applications since it may limit the current-voltage handling capability of these devices and increase power consumption. It has also been reported that the noise performance in GaN-based FET devices is degraded by large leak-

${ }^{a)}$ Electronic mail: sfung@hkucc.hku.hk age current. ${ }^{22}$ These observations, in general, indicate that a more accurate picture of the reverse-bias leakage current dependence on the GaN material quality is needed. In this article, the correlation between the current-voltage $(I-V)$ characteristics of $\mathrm{Au} / n-\mathrm{GaN}$ Schottky diodes fabricated on GaN films with different crystal qualities and dislocation densities have been investigated. A model is proposed to analyze the reverse $I-V$ characteristics of diodes in which a spatial variation of the Schottky barrier height is postulated due to localized screw dislocations in the GaN epilayer at the $\mathrm{Au} / \mathrm{GaN}$ interface. This model also explains why the influence of dislocations on the forward $I-V$ characteristics is found to be negligible except at very small bias. Atomic force microscopy (AFM) images taken after chemical etching confirm the presence of screw dislocations under the Schottky contact and in the GaN films.

\section{EXPERIMENTS}

The starting samples used in the present work were unintentionally doped GaN films grown on $c$-plane sapphire substrates by the metaloganic chemical vapor deposition (MOCVD) method using ammonia $\left(\mathrm{NH}_{3}\right)$ and trimethylgallium (TMG). For the batch A material, the substrate was first heated to $1050{ }^{\circ} \mathrm{C}$ in a stream of hydrogen. The GaN layer was grown at $1030^{\circ} \mathrm{C}$ with $\sim 300$ - $\AA$-thick low-temperature $\left(520^{\circ} \mathrm{C}\right) \mathrm{GaN}$ unintentionally doped buffer layer. For the batch $\mathrm{B}$ material, the substrate was first heated in $\mathrm{H}_{2}$ ambient at $1050^{\circ} \mathrm{C}$ and was then exposed to an ammonia flow of 3 $1 /$ min for $100 \mathrm{~s}$. The temperature was then increased to $1080^{\circ} \mathrm{C}$ for the growth of a 5 - $\mu \mathrm{m}$-thick GaN layer. During the deposition, the typical mole ratio of $\mathrm{NH}_{3}$ and TMG was V/III $\sim 2500$. Samples, belonging to different growth batches $\mathrm{A}$ and $\mathrm{B}$, were cut into square Van der Pauw geometry ( 8 $\mathrm{mm} \times 8 \mathrm{~mm}$ ) for Hall measurement. The GaN samples were first degreased in acetone and methanol in an ultrasonic cleaner. They were put into a boiling mixture solution of $\mathrm{HCl}: \mathrm{H}_{2} \mathrm{O}(1: 1)$ and then were rinsed with deionized water. 
TABLE I. Hall data and etching pit density (EPD) of batch A and B materials. Barrier height, ideality factor, and reverse-bias current density at $-2 \mathrm{~V}$ for Schottky diodes $\left(a_{1}\right),\left(a_{2}\right)$ and $\left(b_{1}\right),\left(b_{2}\right)$ fabricated on batch A and batch $\mathrm{B}$ materials are also listed.

\begin{tabular}{|c|c|c|c|c|c|c|}
\hline Material & $\begin{array}{c}\text { Carrier concentration } \\
\qquad\left(\mathrm{cm}^{-3}\right)\end{array}$ & $\begin{array}{l}\text { Hall mobility } \\
\left(\mathrm{cm}^{2} / \mathrm{V} \mathrm{s}\right)\end{array}$ & $\begin{array}{c}\text { Barrier height } \\
(\mathrm{eV})\end{array}$ & Ideality factor & $\begin{array}{c}\text { Reverse-bias } \\
\text { current density } \\
\text { at }-2 \mathrm{~V} \\
\left(\mathrm{~A} / \mathrm{cm}^{2}\right)\end{array}$ & $\begin{array}{l}\mathrm{EPD} \\
\left(\mathrm{cm}^{-2}\right)\end{array}$ \\
\hline A & $3.2 \times 10^{17}$ & 278 & $\begin{array}{l}a_{1}: 0.913 \\
a_{2}: 0.908\end{array}$ & $\begin{array}{l}1.30 \\
1.33\end{array}$ & $\begin{array}{l}1.835 \times 10^{-7} \\
3.819 \times 10^{-8}\end{array}$ & $4 \times 10^{8}$ \\
\hline B & $3.0 \times 10^{17}$ & 102 & $\begin{array}{l}b_{1}: 0.910 \\
b_{2}: 0.912\end{array}$ & $\begin{array}{l}1.41 \\
1.35\end{array}$ & $\begin{array}{l}1.874 \times 10^{-4} \\
1.258 \times 10^{-5}\end{array}$ & $8.5 \times 10^{8}$ \\
\hline
\end{tabular}

Any oxide layer present was removed by putting the samples into dilute HF solution. They were then rinsed in deionized water before loading into the evaporation chamber. Ohmic contacts were formed by thermally evaporated indium (800 $\AA$ ) followed by $4 \mathrm{~min}$ of $350{ }^{\circ} \mathrm{C}$ annealing in a high-purity $\mathrm{N}_{2}$ ambient. Room-temperature Hall measurements were then carried out in darkness in a magnetic field of $0.5 \mathrm{~T}$ using a BIO-RAD HL5580 Hall effect system. Schottky diodes were fabricated by thermally evaporating gold $(\mathrm{Au})$ film onto the samples in vacuum. The diameter of the Au spot was 400 $\mu \mathrm{m}$. The fabrication process of all the Schottky diodes was kept exactly the same. The $I-V$ characteristics of the Schottky diodes fabricated on the samples obtained from the two batches of materials (i.e., A and B) were measured by a HP4155A semiconductor parameter analyzer. The capacitance-voltage $(C-V)$ properties of the diodes were also measured by the HP 4155A semiconductor parameter analyzer used in conjunction with a Boonton $72 \mathrm{~B}$ capacitance meter.

After the $I-V$ measurements, the samples were soaked in acid solution to remove the metal contacts. These samples were then etched in $\mathrm{H}_{3} \mathrm{PO}_{4}$ at $160{ }^{\circ} \mathrm{C}$ for 30 min to reveal the dislocation density. The surface morphology was subsequently analyzed using a Digital Instrument III atomic force microscope. During the measurements, it was ensured that the AFM images were taken at the same position where the Au metal overlayer originally existed.

\section{RESULTS AND DISCUSSION}

The room-temperature Hall data of the samples from batch A and B materials are listed in Table I. It is noticed that the averaged electron concentration of the batch A sample is $3.2 \times 10^{17} \mathrm{~cm}^{-3}$, which is about the same as the value of $3.0 \times 10^{17} \mathrm{~cm}^{-3}$ for the sample from batch B. The mobility of the batch A sample is $278 \mathrm{~cm}^{2} / \mathrm{V} \mathrm{s}$, which is about two times larger than that of the batch B sample having mobility of about $102 \mathrm{~cm}^{2} / \mathrm{V} \mathrm{s}$.

$I-V$ measurements were conducted for the ten Schottky diodes fabricated from batch $\mathrm{A}$ and $\mathrm{B}$ GaN materials. The current density versus voltage $(J-V)$ curves of four of the Schottky diodes [namely $\left(a_{1}\right)$ and $\left(a_{2}\right)$ from batch A and $\left(b_{1}\right)$ and $\left(b_{2}\right)$ from batch B) are shown in Fig. 1. These four diodes are chosen such that each pair of them, respectively, have the lowest and the highest reverse-bias leakage current among the other diodes in the same batch. As seen from Fig. 1 , all the $J-V$ curves exhibit a good rectifying property.

Using the thermionic emission (TE) model ${ }^{23}$ with values of the effective Richardson constant $A^{*}=24 \mathrm{~A} / \mathrm{cm}^{2} \mathrm{~K}^{2}$ and $m^{*}=0.20 m_{0},{ }^{24}$ the barrier height $\phi_{B}$ and the ideality factor $n$ of the Schottky diodes were determined by fitting the equation

$$
J=A^{*} T^{2} \exp \left(-\frac{q \phi_{B}}{k T}\right) \exp \left(\frac{q V}{n k T}\right),
$$

to the forward $J-V$ characteristics, $q, k$, and $T$ taking their conventional meanings. Equation (1) is valid for $V$ $>3 k T / q$. As seen from Table I, the fitted values of $\phi_{B}$ for Schottky diodes $a_{1}, a_{2}, b_{1}$, and $b_{2}$ are essentially the same, all lying in the range $0.908-0.913 \mathrm{eV}$. The barrier height for the same Schottky diodes was measured by $C-V$ at a frequency of $1 \mathrm{MHz}$, and the obtained value $0.92 \mathrm{eV}$ is in agreement with that obtained from $J-V$ analysis. The ideality factor for the diodes is found to lie in the range between

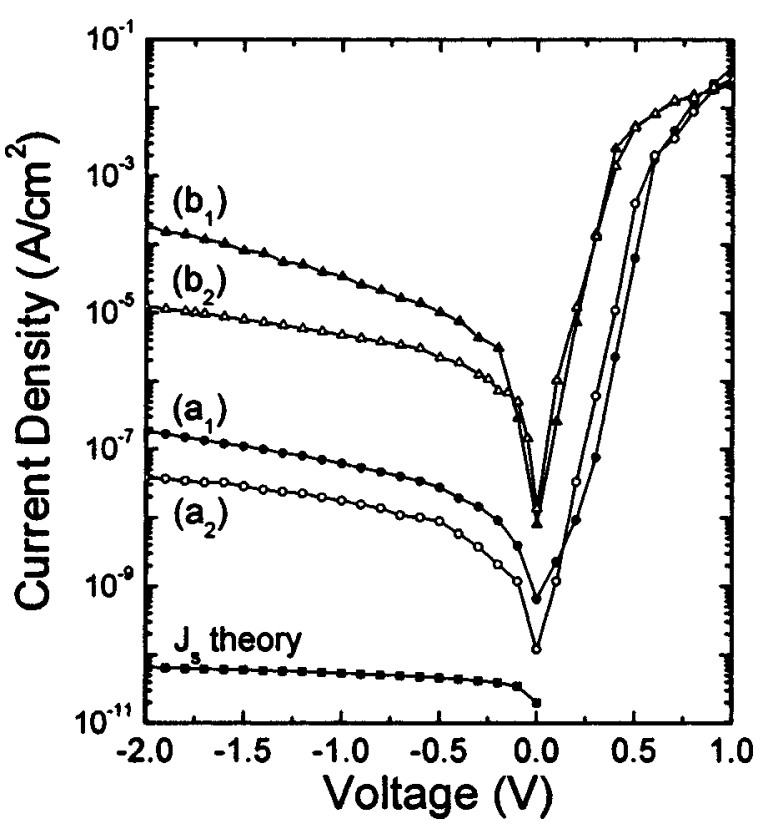

FIG. 1. Current density $(|J|)$ vs bias voltage $(V)$ measured from macroscopic size Schottky diodes. Diodes of curves $\left(a_{1}\right)$ and $\left(a_{2}\right)$ are fabricated on the batch A materials. Diodes of curves $\left(b_{1}\right)$ and $\left(b_{2}\right)$ are fabricated on the batch B materials. Theoretical reverse current density ( $J_{s}$ theory) is also shown. 
1.33 and 1.43. The barrier heights of Schottky diodes in this study are in agreement with previous reported values $(0.80$ $1.1 \mathrm{eV}$ ) for $\mathrm{Au} / n-\mathrm{GaN}$ contacts. ${ }^{25}$ In Fig. 1 , the theoretically calculated reverse leakage current densities $\left(J_{s}\right)$ as given by ${ }^{26}$

$$
J_{S}=A^{*} T^{2} \exp \left(\frac{-q\left(\phi_{B}-\Delta \phi_{B}\right)}{k T}\right),
$$

based on the value $\phi_{B}=0.92 \mathrm{eV}$ (as obtained by $C-V$ ) and an image force reduction in barrier height $\Delta \phi_{B}$ due to the electrical field across the $\mathrm{Au} / \mathrm{GaN}$ interface of ${ }^{26}$

$$
\Delta \phi_{B}=\frac{1}{\sqrt{\pi}}\left(\frac{q}{2 \epsilon_{0} \epsilon_{s}}\right)^{3 / 4} N_{D}^{1 / 4} V_{R}^{1 / 4}
$$

where $V_{R}$ is the applied reverse bias and $N_{D}$ is the semiconductor doping density.

Figure 1 shows the theoretically calculated reverse-bias current density ( $J_{s}$ theory) to be several orders of magnitude lower than the experimentally measured leakage for diodes fabricated on both batch A and B material. The reverse current density also shows a strong dependence on the reverse voltage. Such a dependence is much stronger than the wellknown weak voltage dependence of reverse current in TE transport due to the field dependence of the barrier height. ${ }^{23}$ The same phenomenon has also been reported by Hasegawa et al. in the study of $\mathrm{Ni} / n-\mathrm{GaN}$ and $\mathrm{Pt} / n-\mathrm{GaN}$ Schottky contacts. ${ }^{27}$ Furthermore, the measured reverse-bias current density is seen to strongly depend on the nature of the material on which the Schottky diodes are fabricated. It is observed that diodes fabricated on the batch B material always have larger values of reverse-bias leakage current than those on batch A (refer to Table I and Fig. 1).

The present understanding of the mechanism of reversebiased current flow is rather limited. Shiojima et al. suggested that the maximum electrical field $\left(E_{m}\right)$ at the metal/ semiconductor interface determined the reverse-biased current level. ${ }^{28}$ Hasegawa et al., reporting on $I-V-T$ measurements, suggested that the reverse-bias current could be explained by the thermionic-field emission model. ${ }^{27}$ In the study of Au contacts on MOCVD-grown $n$-GaN it has also been reported that reverse currents were spatially highly nonuniform and that dislocations with a screw component were accompanied by high current density and low effective barrier height. ${ }^{29}$ It is to be expected that morphological and crystallographic defects of the $\mathrm{GaN}$ epilayers would give rise to degradation of the performance of metal/GaN contacts since such defects may introduce lateral variations of the interface electric properties. Here, we follow the lead of Brazel $e t$ al. ${ }^{29}$ in setting up a model that tentatively takes the increased conduction around screw dislocations to be the main reason for the observed current flow. The high reverse leakage current experimentally observed in $\mathrm{Au} / \mathrm{GaN}$ Schottky diodes in the present study is thus modeled on a Schottky barrier height lowering in localized lateral defected (dislocation) regions of the contact. Two regions of the metal/GaN interface were identified: the high Schottky barrier height $(\mathrm{HSBH})$ region arising from the defect-free $\mathrm{Au} /$ $\mathrm{GaN}$ interface (where the barrier height is assumed equal to

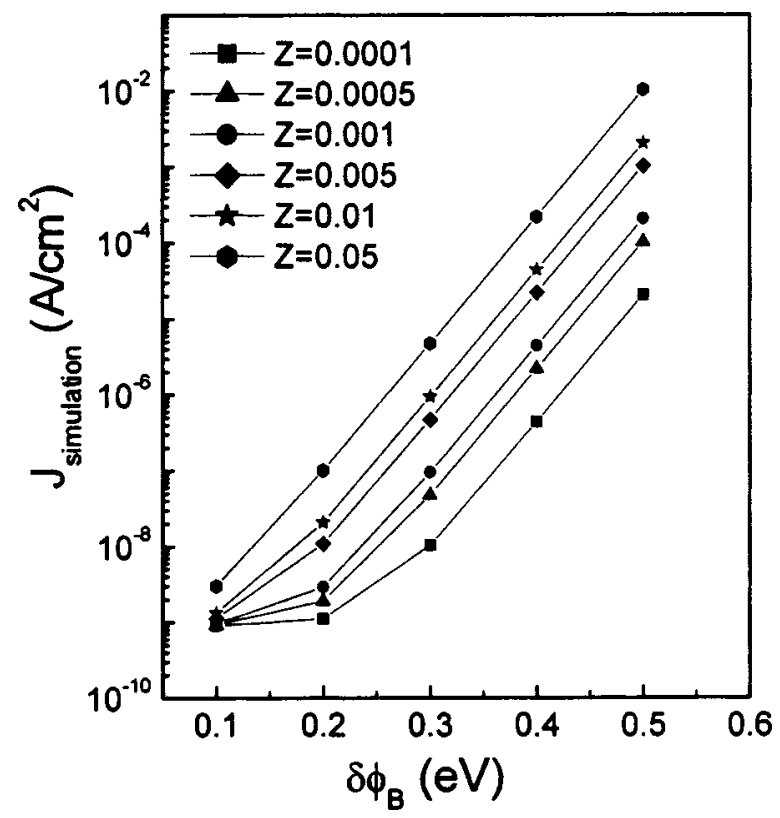

FIG. 2. Simulated leakage current density $J_{\text {simulation }}$ of the Au/GaN Schottky diode as a function of parameters $Z$ and $\delta \phi_{B}$.

the value obtained by $C-V$ measurement) and the summation of all the low Schottky barrier height (LSBH) regions associated with dislocations. The ratio of the area of the LSBH region to the total diode area is defined by the parameter $Z$. In the first approximation these two regions can be regarded as two Schottky diodes connected in parallel. The total reverse-bias saturation current density of the Schottky contact is then given by ${ }^{30}$

$$
J_{S}=J_{S}^{L} Z+J_{S}^{H}(1-Z),
$$

where $J_{S}^{L}$ and $J_{S}^{H}$ are the saturation current densities through the LSBH and HSBH regions, respectively. The difference in the $\operatorname{LSBH}\left(\phi_{L}\right)$ and $\operatorname{HSBH}\left(\phi_{H}\right)$ is defined as $\delta \phi_{B}$.

For a realistic $\mathrm{Au} / \mathrm{GaN}$ Schottky diode, the saturation current density can be modeled by Eq. (4). The saturation current density of an ideal defect-free diode can always be calculated using Eq. (4) with $Z=0$. The simulated saturation current density $J_{\text {simulation }}$ for a diode with $\phi_{B}$ of $0.92 \mathrm{eV}$ (measured by $C-V$ ) as a function of $\delta \phi_{B}$ and $Z$ is shown in Fig. 2. From Fig. 2, it can be seen that for a given temperature and $Z, J_{\text {simulation }}$ strongly increases with $\delta \phi_{B}$, even for a small $Z$ such as 0.001 . Figure 2 also shows a strong dependence of $J_{\text {simulation }}$ on the area ratio $Z$ for a given $\delta \phi_{B}$. Using this analytical model, the influence of dislocations at the $\mathrm{Au} /$ $\mathrm{GaN}$ interface on the reverse $J-V$ characteristics through parameters $Z$ and $\delta \phi_{B}$ are clearly illustrated. In fact, for a diode with large $\delta \phi_{B}$, most of the reverse leakage current flows through the defective region and the contribution from the HSBH region is minimal. Moreover, the barrier height of the $\mathrm{LSBH}$ region need only be $\sim 0.2 \mathrm{eV}$ lower than the HSBH in order to explain our results.

In order to further investigate the reverse-bias leakage current of the Schottky diodes in the present study, AFM combined with wet chemical etching were employed to observe the dislocations in the samples. After the $I-V$ measure- 


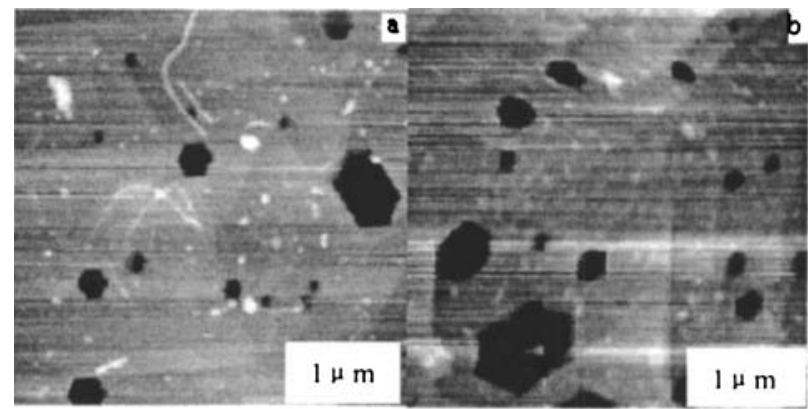

FIG. 3. AFM topography image $(1 \mu \mathrm{m} \times 1 \mu \mathrm{m})$ of $\mathrm{GaN}$ etched by $\mathrm{H}_{3} \mathrm{PO}_{4}$ at $160{ }^{\circ} \mathrm{C}$ for $30 \mathrm{~min}$. (a) Topography image for sample A. (b) Topography image for sample B.

ments, the metal contacts of the diodes were removed using acid. The samples were then etched in hot $\mathrm{H}_{3} \mathrm{PO}_{4}$ at $160^{\circ} \mathrm{C}$ for $30 \mathrm{~min}$. AFM images were taken at the same positions at which the Au Schottky contact was originally located so as to observe the etching pits of the dislocations under the $\mathrm{Au}$ contact in the GaN film. AFM topography images $(1 \mu \mathrm{m} \times 1$ $\mu \mathrm{m}$ area) of etched diodes fabricated from batch $\mathrm{A}$ and $\mathrm{B}$ materials are shown in Fig. 3 and those of the $(4 \mu \mathrm{m} \times 4 \mu \mathrm{m})$ images are shown in Fig. 4. In Fig. 3, the hexagonal etch pits are clearly observed. The AFM images were taken at several different positions and the averaged density of the hexagonal etch pits [etching pit density (EPD)] was calculated from these images. The EPD under the Au electrode of the samples fabricated from the two batches of materials were counted from AFM images and it was found that the averaged EPD of the batch B material is about twice that of the batch A material. The EPD values are list in Table I.

It is known that the shape of the etch pits are well correlated with the types of defects. However, it is not the case that all types of defects would show up as etch pits. For $\mathrm{GaN}$, there are three types of threading dislocations, namely, the screw dislocation (with Burgers vectors type c), the edge dislocation (with Burgers vectors type a), and the mixed dislocations (with Burgers vectors type $\mathbf{c}+\mathbf{a}$ ). ${ }^{31}$ In a similar study of etch pits in MOCVD-grown (0001) GaN etched by $\mathrm{H}_{3} \mathrm{PO}_{4}$, Hong et al. ${ }^{32}$ found that the edge threading dislocation did not form etch pits. It was concluded that the observed etch pits originated from nanopipes having abnormal strain contrast and that these were related to screw dislocations. In another study of Hong et al., careful transmission

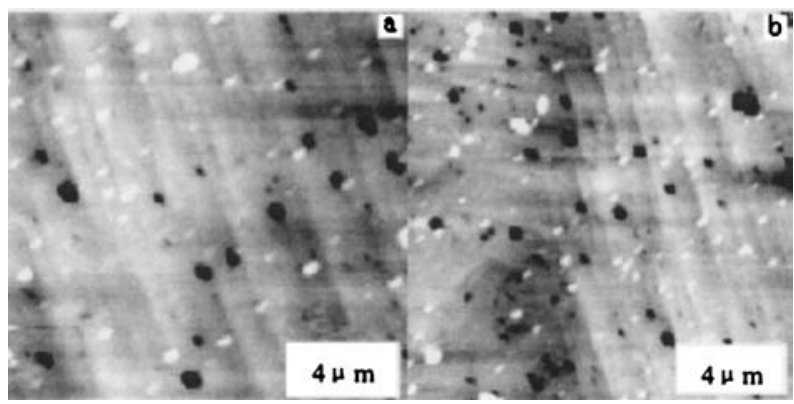

FIG. 4. AFM topography image $(4 \mu \mathrm{m} \times 4 \mu \mathrm{m})$ of $\mathrm{GaN}$ etched by $\mathrm{H}_{3} \mathrm{PO}_{4}$ at $160{ }^{\circ} \mathrm{C}$ for $30 \mathrm{~min}$. (a) Topography image for sample A. (b) Topography image for sample B. electron microscopy (TEM) inspection of etch pits produced by wet chemical etching revealed nanometer-sized hexagonal pits that neither formed at the full-core screw threading dislocations nor at edge dislocations. These etch pits were being formed at nanopipes (i.e., open-core screw dislocations). ${ }^{33}$ Elsner et $a l .{ }^{34}$ have estimated that values of the line energies of full-core screw dislocation, open-core screw dislocation (i.e., dislocation with the nanopipe ${ }^{35}$ ), and edge dislocation to be $7.82 \times 10^{-4}, 7.29 \times 10^{-4}$, and $3.51 \times 10^{-4} \mathrm{erg} \mathrm{cm}^{-1}$, respectively. Thus, it shows that the screw dislocations with nanopipes are preferentially etched because of their high line energy. It should be noted that the size of the etch pits does not correspond to the original size of the nanopipes. The nanopipes also have a hexagonal shape with $\{10-10\}$ facets with sizes ranging from 2 to $50 \mathrm{~nm}{ }^{36}$ It is thus plausible to conclude that the hexagonal-shaped etch pits in the present samples originate from the screw dislocations with nanopipes at their center.

From Figs. 3 and 4, the hexagonal etch pit densities, and thus the density of nanopipes (related to screw dislocations) under the Au Schottky contact, of batch B is higher than that of the batch A material. Previous studies have shown that the screw and mixed dislocations, being more effective recombination centers, are more electrically active than the edge dislocation. ${ }^{19,37,38}$ Using scanning current-voltage microscopy, Hsu et al. ${ }^{19}$ gave direct evidence that reverse bias leakage current of a GaN Schottky diode occurs primarily at dislocations with the screw component. Shiojima et al. ${ }^{39}$ carried out $I-V$ measurements on $\mathrm{Au} / \mathrm{Ni} / n-\mathrm{GaN}$ Schottky contacts using atomic force microscopy with a conductive probe and found that pure edge dislocations do not affect the $I-V$, but that pure screw dislocations and nanopipes could act as leakage paths at the interface. Based on these results and the experimental data of the present study, we can conclude that the large reverse-bias leakage current of diodes fabricated from the batch B material is possibly related to the higher density of the hexagonal etch pit (i.e., screw dislocations with nanopipes at their centers). A very similar phenomenon was also reported by Shiojima et al. ${ }^{40}$ in the study of $\mathrm{Ni}$ Schottky contacts formed on various crystal quality $n$-GaN films. The difference in dislocation density of their GaN film was about double, but the $I-V$ characteristics were completely different with the contacts on high dislocation density film showing more Ohmic-like $I-V$. The higher density of the electrically active screw dislocations at the $\mathrm{Au} / \mathrm{GaN}$ interface of the diodes made on the batch B material would indicate larger values of $Z$ and $\delta \phi_{B}$, and thus larger reversebias leakage current density for these diodes according to the simulation results shown in Fig. 2. This result is consistent with the Hall data. The measured room-temperature Hall mobility of the batch B material is two times lower than that of the batch A material. If we assume that the scattering from the threading edge dislocations are the same for batch A and $B$ materials, then the scattering from electrically active screw dislocations in batch $\mathrm{B}$ is much more prominent than that in batch A material, thus causing the lower mobility of the batch B material.

The influence of screw dislocations on the forward $J-V$ characteristics was not so prominent when compared with 
their influence on the reverse characteristics. In the forward bias region, only at very low biases, most of the current flows through the LSBH region. However, at higher forward biases, the voltage drop across the epitaxial layer resistance becomes large for the LSBH region due to its higher forward current density, and thus the current flow through the LSBH region tends to saturate much faster than the current flow through the HSBH region. This results in the bias dependence of the total forward current becoming dominated by the current flow through the HSBH region. The inhomogeneity of the Schottky barrier height thus may be effectively negligible at higher forward biases. This may explain why in spite of the large variations of Schottky barrier height postulated at dislocations, the barrier heights obtained from the forward $J-V 0.908-0.912 \mathrm{eV}$, are essentially the same as those obtained using $C-V$. Moreover, it would also explain why the ideality factor $n(1.33-1.43)$ is relatively large, indicating that the Schottky diodes in the present study cannot be described by an ideal thermionic emission model. This observation clearly needs further investigation. A slightly higher $n$ value was also reported in the study of submicrometer Schottky contacts on $n$-GaN, and it was suggested that the higher $n$ would be related to GaN quality, surface treatment, or process-induced damages during the metal deposit. $^{28}$

In summary, the current-voltage characteristics of $\mathrm{Au} / n$-GaN Schottky diodes fabricated on (0001) epitaxial $\mathrm{GaN}$ layers were investigated. AFM observations after chemical etching have been used to identify the dislocations in the GaN under the Schottky contact. The screw dislocations with nanopipes at their center have been found to have a significant influence on the reverse-bias $J-V$ characteristics. A model for thermionic current flow has been developed based on the recent suggestion that screw dislocations form localized regions at the $\mathrm{Au} / \mathrm{GaN}$ interface where the Schottky barrier height is lowered. Analytical calculations of the $\mathrm{Au} / n$-GaN Schottky contact with barrier height inhomogeneities have been carried out to study the effect of localized regions with barrier height lowering. The ratio of the effective summed defected area $(Z)$ and the barrier height lowering in these areas $\left(\delta \phi_{B}\right)$ are shown to be important parameters that can significantly effect the reverse-bias leakage current. It is found that the reverse leakage current is increased drastically when there exists a high density of screw dislocations under the Au Schottky contact and that the diode characteristics in forward bias are determined largely by the nondefected (HSBH) $\mathrm{Au} / n-\mathrm{GaN}$ interface.

\section{ACKNOWLEDGMENTS}

The work described in this article is partially supported by the grants from the Research Grant Council of the Hong Kong Special Administrative Region, China (under Project Nos. HKU7103/02P, HKU7104/98P, HKU7091/00P, and HKU1/00C) and the Hung Hing Ying Physical Science Research Fund.

${ }^{1}$ G. Parish, S. Keller, P. Kozodoy, J. P. Ibbetson, H. Marchand, P. T. Fini, S. B. Fleischer, S. P. DenBaars, U. K. Michra, and E. J. Tarsa, Appl. Phys. Lett. 75, 247 (1999).
${ }^{2}$ U. V. Bhapkar and M. S. Shur, J. Appl. Phys. 82, 1649 (1997).

${ }^{3}$ Q. Chen, M. Asif Khan, J. W. Yang, C. J. Sun, M. S. Shur, and H. Park, J. Appl. Phys. 69, 794 (1996).

${ }^{4}$ L. S. McCarthy, P. Kozodoy, M. J. W. Rodwell, S. P. DenBaars, and U. K. Mishra, IEEE Electron Device Lett. 35, 277 (1999).

${ }^{5}$ S. Yoshida and J. Suzuki, Jpn. J. Appl. Phys., Part 2 38, L851 (1999).

${ }^{6}$ S. Nakamura, Oyo Butsuri 68, 793 (1999).

${ }^{7}$ J. Kolnik, I. H. Oguzman, K. F. Brennan, Wang Rongping, and P. P. Ruden, J. Appl. Phys. 81, 726 (1997).

${ }^{8}$ S. C. Jain, M. Willander, J. Narayan, and R. Van Overstraeten, J. Appl. Phys. 87, 965 (2000).

${ }^{9}$ S. C. Binari, H. B. Dietrich, G. Kelner, L. B. Rowland, K. Doverspike, and D. K. Gaskill, Electron. Lett. 30, 909 (1994).

${ }^{10}$ A. C. Schmitz, A. T. Ping, M. Asif Khan, Q. Chen, J. W. Wang, and I. Adesida, Semicond. Sci. Technol. 11, 1464 (1996).

${ }^{11}$ L. Wang, M. I. Nathan, T. Lim, M. Asif Khan, and Q. Chen, Appl. Phys. Lett. 68, 1267 (1996).

${ }^{12}$ J. D. Guo, M. S. Feng, R. J. Guo, F. M. Pan, and C. Y. Chang, Appl. Phys. Lett. 67, 2657 (1995).

${ }^{13}$ S. N. Mohammad, A. A. Salvador, and H. Morko, Proc. IEEE 83, 1306 (1995).

${ }^{14}$ P. Hacke, T. Detchprohm, K. Hiramatsu, and N. Sawaki, Appl. Phys. Lett. 63, 1214 (1993).

${ }^{15}$ M. R. H. Khan, T. Detchprom, P. Hacke, K. Hiramatsu, and N. Sawaki, J. Phys. D 28, 1169 (1995).

${ }^{16}$ S. Tomiya, E. Morita, M. Ukita, H. Okuyama, S. Itoh, K. Nakano, and A. Ishibashi, Appl. Phys. Lett. 66, 1208 (1995).

${ }^{17}$ L. McCarthy, I. Smorchkova, H. Xing, P. Fini, S. Keller, J. Speck, S. P. DenBaars, M. J. W. Rodwell, and U. K. Mishra, Appl. Phys. Lett. 78, 2235 (2001).

${ }^{18}$ P. Kozodoy, J. P. Ibbetson, H. Marchand, P. T. Fini, S. Keller, J. S. Speck, S. P. DenBaars, and U. K. Mishra, Appl. Phys. Lett. 73, 975 (1998).

${ }^{19}$ J. W. P. Hsu, M. J. Manfra, D. V. Lang, S. Richter, S. N. G. Chu, A. M. Sergent, R. N. Kleiman, L. N. Pfeiffer, and R. J. Molnar, Appl. Phys. Lett. 78, 1685 (2001).

${ }^{20}$ J. C. Carrano, T. Li, P. A. Grudowski, C. J. Eiting, R. D. Dupuis, and J. C. Campbell, J. Appl. Phys. 83, 6148 (1998).

${ }^{21}$ E. J. Miller, D. M. Schaadt, E. T. Yu, C. Poblenz, C. Elsass, and J. S. Speck, J. Appl. Phys. 91, 9821 (2002).

${ }^{22}$ S. L. Rumyantsev, N. Pala, M. S. Shur, R. Gaska, M. E. Levinshtein, M. Asif Khan, G. Simin, X. Hu, and J. Yang, J. Appl. Phys. 88, 6726 (2000).

${ }^{23}$ E. H. Rhoderick and R. H. Williams, Metal-Semiconductor Contacts, 2nd ed. (Clarendon, Oxford, 1998).

${ }^{24}$ A. S. Barker and M. Ilegems, Phys. Rev. B 7, 743 (1973).

${ }^{25}$ S. K. Noh and P. Bhattacharya, Appl. Phys. Lett. 71, 3642 (2001).

${ }^{26}$ S. M. Sze, Physics of Semiconductor Devices (Wiley, New York, 1981).

${ }^{27}$ H. Hasegawa and S. Oyama, J. Vac. Sci. Technol. B 20, 1647 (2002).

${ }^{28}$ K. Shiojima and T. Suemitsu, J. Vac. Sci. Technol. B 21, 698 (2003).

${ }^{29}$ E. G. Brazel, M. A. Chin, and V. Narayanamurti, Appl. Phys. Lett. 74, 2367 (1999).

${ }^{30}$ M. Bhatnagar, B. Jayant Baliga, H. R. Kirk, and G. A. Rozgonyi, IEEE Trans. Electron Devices 43, 150 (1996).

${ }^{31}$ F. A. Ponce, D. Cherns, W. T. Young, and J. W. Steeds, Appl. Phys. Lett. 69, 770 (1996).

${ }^{32}$ S. K. Hong, B. J. Kim, H. S. Park, S. Y. Yoon, and T. I. Kim, J. Cryst. Growth 191, 275 (1998).

${ }^{33}$ S. K. Hong, T. Yao, B. J. Kim, S. Y. Yoon, and T. I. Kim, Appl. Phys. Lett. 77, 82 (2000).

${ }^{34}$ J. Elsner, R. Jones, P. K. Sitch, V. D. Porezag, M. Elstner, Th. Frauenheim, M. I. Heggie, S. Öberg, and P. R. Briddon, Phys. Rev. Lett. 79, 3672 (1997).

${ }^{35}$ J. L. Rouviere, M. Arlery, B. Daudin, G. Feuillet, and O. Briot, Mater. Sci. Eng., B 50, 61 (1997).

${ }^{36}$ W. Qian, G. S. Rohrer, M. Skowronski, K. Doverspike, L. B. Rowland, and D. K. Gaskill, Appl. Phys. Lett. 67, 2284 (1995).

${ }^{37}$ T. Hino, S. Tomiya, T. Miyajima, K. Yanashima, S. Hashimoto, and M. Ikeda, Appl. Phys. Lett. 76, 3421 (2000).

${ }^{38}$ D. Cherns, S. J. Henley, and F. A. Ponce, Appl. Phys. Lett. 78, 2691 (2001).

${ }^{39}$ K. Shiojima, T. Suemitsu, and M. Ogura, Appl. Phys. Lett. 78, 3636 (2001).

${ }^{40}$ K. Shiojima, J. M. Woodall, C. J. Eiting, P. A. Grudowski, and R. D. Dupuis, J. Vac. Sci. Technol. B 17, 2030 (1999). 